\title{
Perceived Ethnic Discrimination and Depressive Symptoms Among Biethnic Adolescents in South Korea
}

\author{
Gum Ryeong Park', Inseo Son'2, Seung-Sup Kim ${ }^{3,4,5}$ \\ ${ }^{1}$ Social Insurance Research Department, Korea Institute for Health and Social Affairs, Sejong; ${ }^{2}$ Asiatic Research Institute, Korea University, Seoul; \\ ${ }^{3}$ Department of Public Health Sciences, Graduate School of Korea University, Seoul, Korea; ${ }^{4}$ Department of Environmental and Occupational \\ Health, Milken Institute School of Public Health at George Washington University, Washington, DC; ${ }^{5}$ Department of Social and Behavioral Sciences, \\ Harvard T. H. Chan School of Public Health, Boston, MA,USA
}

Objectives: This study investigated the association between perceived ethnic discrimination and depressive symptoms among biethnic adolescents in South Korea.

Methods: We performed a cross-sectional study of 4141 biethnic adolescents using data from the 2012 National Survey of Multicultural Families. Perceived ethnic discrimination was measured using the question "Have you ever been discriminated against or ignored because either of your parents is not a Korean?" with an assessment of depressive symptoms over the past 12 months. Logistic regression was applied to examine potential associations between perceived ethnic discrimination and depressive symptoms.

Results: Among 4141 biethnic adolescents, 558 (13.5\%) reported having experienced ethnic discrimination. The most common discriminatory perpetrators were friends $(n=241,5.8 \%)$, followed by strangers $(n=67,1.6 \%)$. Depressive symptoms were related to experience of ethnic discrimination (odds ratio [OR], 3.80; 95\% confidence interval [Cl], 2.89 to 4.98) after adjusting for potential confounders. In an analysis focusing on the perpetrators of discrimination, depressive symptoms were found to be associated with perceived ethnic discrimination from friends $(\mathrm{OR}, 3.95 ; 95 \% \mathrm{Cl}, 2.75$ to 5.68$)$, teachers $(\mathrm{OR}, 4.53 ; 95 \% \mathrm{Cl}, 2.16$ to 9.51$)$, family members and relatives (OR, 3.89; $95 \% \mathrm{Cl}, 1.59$ to 9.48$)$, neighbors (OR, 2.48; $95 \% \mathrm{Cl}, 1.14$ to 5.38$)$, and strangers (OR, 2.49; $95 \% \mathrm{Cl}, 1.30$ to 4.79$)$. Furthermore, the OR for depressive symptoms among those exposed to 1, 2, or 3 or more discriminatory perpetrators were 3.61 (95\% $\mathrm{Cl}$, 2.49 to 5.24$)$, $3.61(95 \% \mathrm{Cl}, 1.68$ to 7.74$)$, and 6.69 (95\% Cl, 2.94 to 15.22$)$, respectively.

Conclusions: According to our findings, friends were the most common perpetrators of discrimination and the experience of ethnic discrimination was associated with depressive symptoms among biethnic adolescents in South Korea.

Key words: Discrimination, Depression, Republic of Korea

\section{INTRODUCTION}

Received: April 14, 2016 Accepted: August 24, 2016

Corresponding author: Seung-Sup Kim, MD, ScD

145 Anam-ro, Seongbuk-gu, Seoul 02841, Korea

Tel: +82-2-3290-5676, Fax: +82-2-916-5943

E-mail: ssk3@korea.ac.kr

This is an Open Access article distributed under the terms of the Creative Commons Attribution Non-Commercial License (http://creativecommons.org/licenses/bync/4.0/) which permits unrestricted non-commercial use, distribution, and reproduction in any medium, provided the original work is properly cited.
An unprecedented increase in international marriages and the resulting massive influx of immigrants have altered the ethnic composition of the purportedly ethnically homogeneous society of South Korea (hereafter Korea) [1]. Most foreign spouses marrying Koreans are females who immigrated for marriage, who are often known as marriage immigrants. Korea has shown a more dramatic increase in sex-specific in- 
ternational marriages than other industrialized Asian countries, such as Taiwan, Singapore, and Japan [2]. The total number of marriage immigrants (country of origin: China, $60.0 \%$; Vietnam, 5.4\%; and Japan, 4.4\%) living in Korea was 281295 in 2013, two times higher than the number of 142015 reported in 2007 [3]. The growth of international marriages in Korea has resulted in a rapid increase of children born into such families; the number of these children rose from 26015 in 2009 to 55780 in 2013, and such children accounted for $0.9 \%$ of all adolescents in Korea [3].

Discrimination has emerged as a critical issue in countries with a large immigrant population, and social integration may be most strongly threatened by the ethnocentrism of natives. Ethnic or racial discrimination against immigrants and their children is still prevalent in Organization for Economic Cooperation and Development (OECD) countries with a long history of immigration [4]. In addition, countries that have only recently begun to receive immigrants, mostly developed Asian countries, have difficulties in integrating immigrants into their societies. In Korea, marriage immigrants and their biethnic adolescents are common targets of discrimination, which has become a social problem, despite their increasing numbers $[5,6]$.

Accordingly, the Korean government has recently initiated a series of social welfare programs to further the social integration of biethnic families. However, marriage immigrants and their children still do not enjoy the same social mobility and legal rights as Korean citizens [7,8]. Although they are naturalized citizens, biethnic adolescents are stereotyped as ethnic others. According to the World Values Survey, in questions regarding intolerance toward racially diverse neighbors, Korea showed the second highest level of intolerance among 15 OECD countries (Figure 1) [9].

A growing amount of public health research indicates that discrimination based on race or ethnicity is likely to damage the physical and mental health of those who experience discrimination [10]. Furthermore, adolescents are considered sensitive to adverse social experiences such as discrimination. In addition, early traumatic experiences such as discrimination have lifelong impacts that impede the psychological and physical development of adolescents $[11,12]$. Some studies have reported that ethnic discrimination among marriage immigrants in Korea has a direct impact on health status, including self-rated health $[6,13]$. However, few studies have investigated ethnic discrimination towards biethnic adolescents in Korea.

This study aimed to investigate the prevalence of perceived ethnic discrimination among biethnic adolescents in Korea

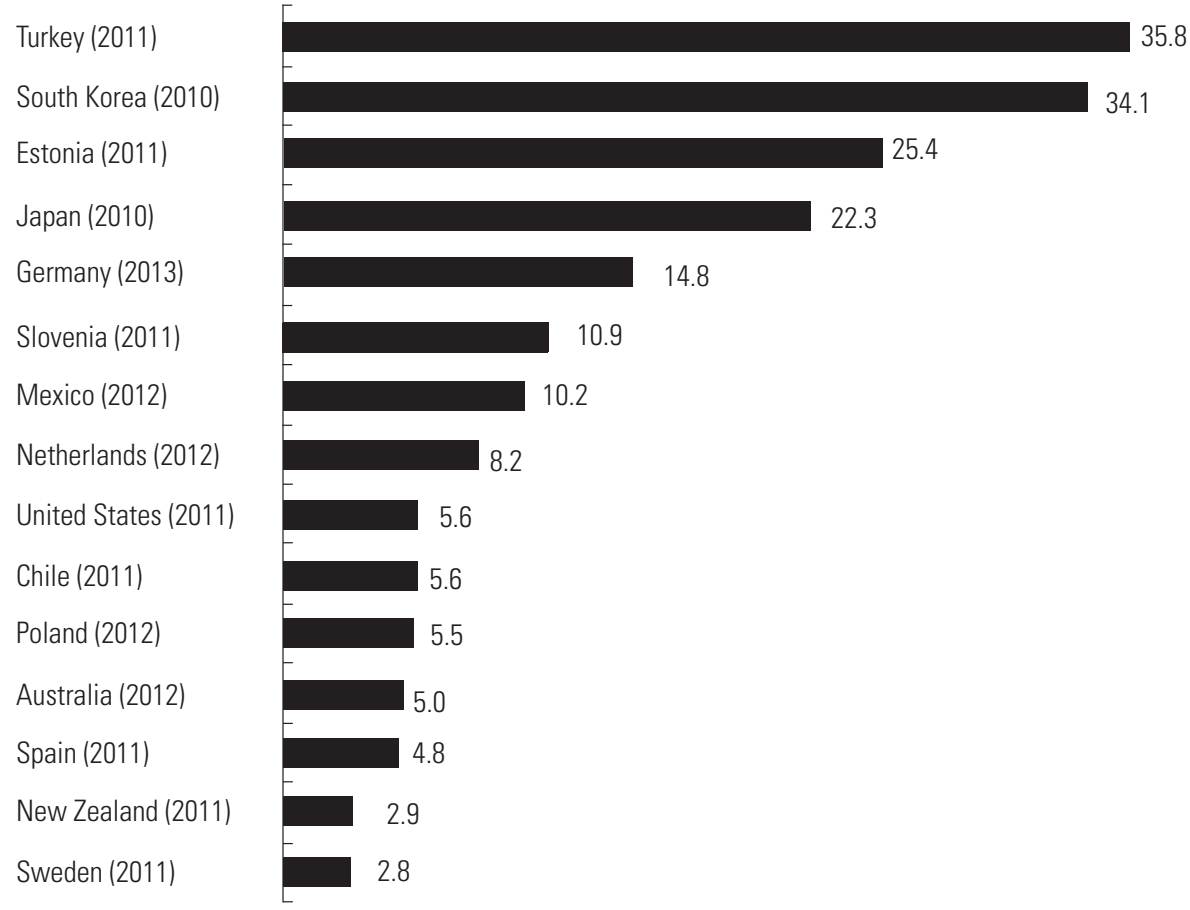

Figure 1. Proportion of people who would not like to have people of different race as their neighbors among 15 Organization for Economic Cooperation and Development countries (\%). From World Values Survey. World values survey wave 6: 2010-2014 [9]. 
and its association with depressive symptoms. Our research addressed the following questions.

1. What is the prevalence of perceived ethnic discrimination among biethnic adolescents in Korea?

2. Who are the common perpetrators of perceived ethnic discrimination towards biethnic adolescents in Korea?

3. Is there an association between perceived ethnic discrimination and depressive symptoms among biethnic adolescents in Korea?

\section{METHODS}

\section{Data Collection}

We analyzed data from the 2012 National Survey of Multicultural Families (NSMF) conducted by the Korean Women's Development Institute (http://eng.kwdi.re.kr/). Data were collected from July 12, 2012 to July 31, 2012 using two-step sampling. In the first step, systematic sampling was used to select 850 districts from the 3470 administrative districts that contained at least one multicultural family. In the second step, 26 098 families were selected from 71933 multicultural families in these 850 administrative districts based on the type of district and nationality of the family, using stratified sampling. UItimately, 33635 participants (15 001 immigrants, 13859 partners, and 4775 biethnic adolescents) from 15341 families responded to a survey questionnaire (response rate, 15341 of 26 098, 59.0\%). Among 4775 biethnic adolescents, 4141 were selected as the study population after excluding those over 18 years of age and those with missing responses in the questionnaire.

\section{Measures}

\section{Perceived ethnic discrimination}

Perceived ethnic discrimination was measured using the question "Have you ever been discriminated against or ignored because either of your parents is not a Korean national?" Biethnic adolescents could respond "yes" or "no" to this question. Adolescents who responded "yes" were allowed to select multiple perpetrators from the following list: friends, teachers, family members and relatives, neighbors, and strangers. Biethnic adolescents were asked to rate the severity of discrimination experienced from each category of perpetrator on a 4-point ordinal scale ranging from one (severe discrimination) to four (absolutely no discrimination). Respondents were classified into two categories: those who reported discriminatory experiences (responses of 1 or 2 ) and those who did not (responses of 3 or 4). Participants were given the option of replying "not applicable." Subsequently, those responses were excluded when we examined associations between perceived ethnic discrimination from each perpetrator and depressive symptoms. In addition, we created a new variable by aggregating the number of perpetrators (range, $0-5$ ) to examine the association between the number of discriminatory perpetrators and depressive symptoms.

\section{Depressive symptoms}

Depressive symptoms were measured using a single-item question: "During the past 12 months, have you ever felt sad or hopeless and been unable to complete daily activities for two weeks or more?" Respondents could answer on a 4-point Likert scale from 1 (never) to 4 (very often). Respondents were classified into two categories based on their answers: having depressive symptoms (responses of 3 or 4 ) and not having depressive symptoms (responses of 1 or 2). This measure has been used in previous studies and in national statistical analyses, such as the Korea National Health and Nutrition Examination Survey conducted by the Ministry of Health and Welfare and the Korea Centers for Disease Control and Prevention $[14,15]$.

\section{Potential confounders}

We included sex, age, educational status, country of origin of the immigrant parent, birthplace, household income, parents' perceived socioeconomic status in Korea, and Korean language fluency as potential confounders for the data analysis. Participants were classified according to age into three categories; 9-11, 12-15, and 16-18 years. Participants were divided into three categories reflecting educational status: currently attending school, currently not attending school, and having finished school. We included the country of origin of the immigrant parent as a categorical variable: China, Korean-Chinese, Taiwan, Hong Kong, Japan, Mongolia, Vietnam, Philippines, Thailand, Cambodia, Russia, Uzbekistan, the European Union, US, Canada, and other. Participants were divided according to monthly household income into five categories: less than 1 million Korean won (KRW), 1-3 million KRW, 3-5 million KRW, 5-7 million KRW, and 7 million KRW or higher. Perceived socioeconomic status in Korea was measured by asking the parents of the adolescents the following question: "What is the socioeconomic status of your family in Korea?" Responses were pro- 
vided on an 11-point Likert scale ranging from 1 (very low) to 11 (very high). Responses were classified into three groups: low (responses of 1 to 4), middle (responses of 5 to 7), or high (responses of 8 to 11). In addition, in order to assess Korean language fluency among biethnic adolescents, four different domains of language skills (listening, speaking, writing, and reading) were self-evaluated. For each domain, respondents evaluated their ability using a 5-point ordinal scale ranging from 1 (very poor) to 5 (fluent). We summarized the scores from each domain and classified the resulting score into three categories: good (4), fair (5-7), and fluent (8-20).

\section{Analysis}

First, we compared the prevalence of experiences of discrimination using the chi-square test. We also examined the prevalence of depressive symptoms by stratification according to each potential confounder. Second, logistic regression was applied to examine the relationship of depressive symptoms with any type of ethnic discrimination and with ethnic discrimination from each of the five possible types of perpetrator. Third, we sought to investigate the relationship between the number of perpetrators of discrimination and depressive symptoms. All potential confounders were included as categorical variables. We conducted data analysis using the Huber-

Table 1. Distribution and prevalence of ethnic discrimination and depressive symptoms among biethnic adolescents in Korea $(n=4141)$

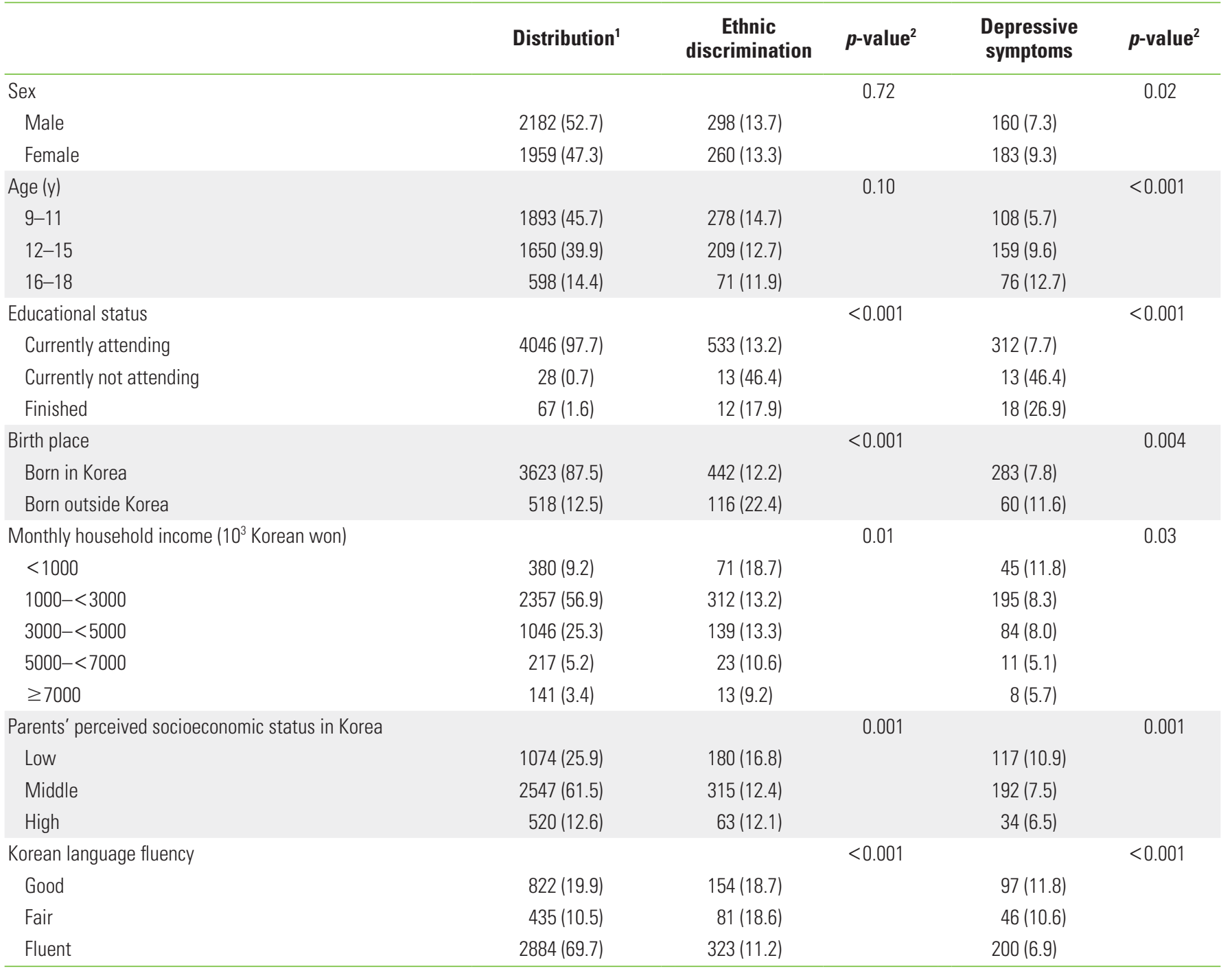

Values are presented as number (\%).

${ }^{1}$ The distribution by the country of origin of the immigrant parent is not shown in this table.

${ }^{2}$ Chi-square test comparing prevalence of perceived ethnic discrimination by each potential confounder. 
White sandwich estimator because participants from the same family may have had similar depressive symptoms [16,17]. Associations were summarized as odds ratios (ORs) with $95 \%$ confidential intervals (Cls). Stata/SE version 12.0 (StataCorp, College Station, TX, USA) was used for the statistical analysis.

\section{Ethics}

This research received institutional review board exemption from the Office of Human Research Administration at the Korea University .

\section{RESULTS}

The total prevalence of perceived ethnic discrimination among the study population was $13.5 \%$. The prevalence of perceived ethnic discrimination was significantly higher for biethnic adolescents who were born outside Korea (22.4\%) and whose Korean language fluency was good (18.7\%), as shown in Table 1. Depressive symptoms were more common among biethnic adolescents who were from 16 to 18 years old (12.7\%) and whose parents' perceived status in Korea was low (10.9\%).

Friends were the most common perpetrators of discrimination ( $n=241,5.8 \%)$, followed by strangers $(n=67,1.6 \%)$, neighbors $(n=47,1.1 \%)$, teachers $(n=43,1.0 \%)$, and family members and relatives $(n=29,0.7 \%)$ (Table 2). The association between any type of perceived ethnic discrimination and de- pressive symptoms was statistically significant among biethnic adolescents (OR, 4.26; 95\% Cl, 3.31 to 5.47). This association remained significant (OR, 3.80; $95 \% \mathrm{Cl}, 2.89$ to 4.98$)$ after adjusting for potential confounders, including parents' perceived status in Korea and the country of origin of the immigrant parent. The ORs for the relationship of discrimination from friends, teachers, family members and relatives, neighbors, and strangers with depressive symptoms were $3.95(95 \% \mathrm{Cl}, 2.75$ to 5.68), $4.53(95 \% \mathrm{Cl}, 2.16$ to 9.51$), 3.89(95 \% \mathrm{Cl}, 1.59$ to 9.48$), 2.48$ ( $95 \% \mathrm{Cl}, 1.14$ to 5.38$)$, and $2.49(95 \% \mathrm{Cl}, 1.30$ to 4.79$)$, respectively, after adjusting for all potential confounders.

Finally, we found an association between the number of perpetrators of ethnic discrimination and depressive symptoms among biethnic adolescents. The OR for depressive symptoms of those who were exposed to one type of perpetrator was 3.61 (95\% Cl, 2.49 to 5.24). However, for those exposed to more than three types of perpetrators, the OR of having depressive symptoms was $6.69(95 \% \mathrm{Cl}, 2.94$ to 15.22), which was higher than the ORs of other groups.

\section{DISCUSSION}

This study investigated the prevalence of perceived ethnic discrimination among biethnic adolescents and its association with depressive symptoms. First, more than $10 \%$ of adolescents reported experiencing ethnic discrimination. This find-

Table 2. Association between ethnic discrimination by perpetrators and depressive symptoms among biethnic adolescents in Korea $(n=4141)$

\begin{tabular}{|c|c|c|c|}
\hline & n (\%) & Unadjusted & Adjusted $^{1}$ \\
\hline Any discrimination & $558(13.5)$ & $4.26(3.31,5.47)^{* * *}$ & $3.80(2.89,4.98)^{* *}$ \\
\hline \multicolumn{4}{|l|}{ Perpetrator of discrimination } \\
\hline Friends & $241(5.8)$ & $4.81(3.46,6.69)^{* * *}$ & $3.95(2.75,5.68)^{* * *}$ \\
\hline Teachers $^{2}$ & $43(1.0)$ & $5.53(2.95,10.37)^{* * *}$ & $4.53(2.16,9.51)^{* * *}$ \\
\hline Family members and relatives ${ }^{3}$ & $29(0.7)$ & $5.09(2.33,11.11)^{* * *}$ & $3.89(1.59,9.48)^{* *}$ \\
\hline Neighbors & $47(1.1)$ & $4.36(2.18,8.72)^{* * *}$ & $2.48(1.14,5.38)^{*}$ \\
\hline Strangers & $67(1.6)$ & $4.24(2.31,7.76)^{* * *}$ & $2.49(1.30,4.79)^{* *}$ \\
\hline \multicolumn{4}{|l|}{ No. of perpetrators of discrimination } \\
\hline 0 & 3839 (92.7) & 1.00 (reference) & 1.00 (reference) \\
\hline 1 & $229(5.5)$ & $4.06(2.89,5.70)^{* * *}$ & $3.61(2.49,5.24)^{* * *}$ \\
\hline 2 & $42(1.0)$ & $5.39(2.64,11.00)^{* * *}$ & $3.61(1.68,7.74)^{* *}$ \\
\hline$\geq 3$ & $31(0.7)$ & $9.74(4.60,20.64)^{* * *}$ & $6.69(2.94,15.22)^{* * *}$ \\
\hline
\end{tabular}

Values are presented as odds ratio (95\% confidence interval).

${ }^{1}$ Adjusted for sex, age, educational status, a country of origin of immigrant parent, birth place, monthly household income, parents' perceived socio economic status in Korea and Korean language fluency.

${ }^{2}$ Nine adolescents who answered "not applicable" for the question about discrimination from teachers excluded from analysis.

${ }^{3}$ Six adolescents who answered "not applicable" for the question about discrimination from relative excluded from analysis.

${ }^{*} p<0.05,{ }^{* *} p<0.01,{ }^{* * *} p<0.001$. 
ing suggests that ethnicity is one of the main sources of social exclusion in Korea. Second, perceived ethnic discrimination was significantly associated with depressive symptoms among biethnic adolescents in Korea. This finding is consistent with previous studies of associations between ethnic discrimination and mental health among minority youth [18-23]. Third, we found that friends were the most common perpetrators (5.8\%) and that the OR of having depressive symptoms was highest among biethnic adolescents who had perceived ethnic discrimination from teachers $(\mathrm{OR}, 4.53 ; 95 \% \mathrm{Cl}, 2.16$ to 9.51). These findings suggest that perceived ethnic discrimination in school has a more detrimental effect on mental health than discrimination in other settings, and this dynamic may negatively impact the development of biethnic children [20, $23,24]$. The prevalence of ethnic discrimination and its strong association with depressive symptoms in school settings have implications for the integration of biethnic adolescents into schools.

To our knowledge, this study is the first to report the prevalence of perceived ethnic discrimination and perpetrators and to investigate associations between perceived ethnic discrimination and depressive symptoms among biethnic adolescents living in Korea. We analyzed a large study population ( $\mathrm{n}=$ 4141 ), which corresponds to $2.5 \%$ of the total number of biethnic adolescents $(n=168583)$ living in Korea as of 2012 [3].

However, several limitations of this study should be noted. First, we were not able to provide temporal information regarding the association between perceived ethnic discrimination and depressive symptoms among biethnic adolescents due to the cross-sectional design of the survey. For example, it is possible that biethnic adolescents with poor health were more likely to experience ethnic discrimination. Second, information bias regarding the experience of ethnic discrimination is possible due to the self-reported nature of the responses, as has been previously discussed [21,22,25-27]. Third, the prevalence of perceived ethnic discrimination among respondents was lower than expected in comparison to other studies, particularly studies dealing with minorities in the US [28]. The NSMF contains a single question about experiences of discrimination, which might lead to a lower response rate. Many studies have suggested that discrimination incorporates a wide spectrum of actions, from physical attacks to nuanced verbal labeling [29]. Therefore, it is necessary to develop questionnaires that measure different aspects of discrimination. Fourth, depressive symptoms were assessed by a single item; therefore, this study used this measure after dichotomization into a category corresponding to the presence of depressive symptoms (scores of 3 or 4 ) and a category reflecting the absence of depressive symptoms (scores of 1 or 2). Our findings remained consistent when we conducted a post-hoc analysis with a different cut-off to screen for biethnic adolescents with depressive symptoms (2-4) or not (1) (results not shown). Further studies should address these shortcomings.

Ethnic discrimination is a critical risk factor for health outcomes such as depressive symptoms. Our study showed that individual experiences of ethnic discrimination remain an important issue for biethnic adolescents in Korea. Future studies are needed to improve interventions and policies to reduce ethnic discrimination.

\section{ACKNOWLEDGEMENTS}

This work was supported by Ministry of Education of the Republic of Korea and the National Research Foundation of Korea (NRF-2015S1A3A2046566).

\section{CONFLICT OF INTEREST}

The authors have no conflicts of interest associated with the material presented in this paper.

\section{ORCID}

Gum Ryeong Park http://orcid.org/0000-0003-0696-9421

Inseo Son http://orcid.org/0000-0002-9507-1324

Seung-Sup Kim http://orcid.org/0000-0003-1830-0282

\section{REFERENCES}

1. Lee Y. Migration, migrants, and contested ethno-nationalism in Korea. Crit Asian Stud 2009;41(3):363-380.

2. Jones GV, Shen HH. International marriage in East and Southeast Asia: trends and research emphases. Citizensh Stud 2008;12(1):9-25.

3. Statistics Korea. Adolescent statistics 2013 [cited 2014 Mar 3]. Available from: http://kostat.go.kr/portal/korea/kor_nw/2/1/ index.board? bmode $=$ read\&aSeq $=287091$ (Korean).

4. Organization for Economic Cooperation and Development. Indicators of immigrant integration 2015 [cited 2016 Sep 4]. Available from: http://www.oecd.org/els/mig/Indicators-of- 
Immigrant-Integration-2015.pdf.

5. Chun JS, Chung Y. A comparison of path factors influencing depressive symptoms in children of immigrant women and Korean children in South Korea. Child Youth Serv Rev 2011;33 (11):2087-2095.

6. Lee S, Kim DS. Acculturation and self-rated health among foreign women in Korea. Health Soc Welf Rev 2014;34(2):453483.

7. Kim M. Citizenship projects for marriage migrants in South Korea: intersecting motherhood with ethnicity and class. Soc Pol 2013. http://dx.doi.org/10.1093/sp/jxt015.

8. Bélanger D, Lee HK, Wang HZ. Ethnic diversity and statistics in East Asia: 'foreign brides' surveys in Taiwan and South Korea. Ethn Racial Stud 2010;33(6):1108-1130.

9. World Values Survey. World values survey wave 6: 2010-2014 [cited 2016 Sep 20]. Available from: http://www.worldvaluessurvey.org/WVSOnline.jsp.

10. Krieger N. Discrimination and health inequities. Int J Health Serv 2014;44(4):643-710.

11. Priest N, Paradies Y, Trenerry B, Truong M, Karlsen S, Kelly Y. A systematic review of studies examining the relationship between reported racism and health and wellbeing for children and young people. Soc Sci Med 2013;95:115-127.

12. Wong CA, Eccles JS, Sameroff A. The influence of ethnic discrimination and ethnic identification on African American adolescents'school and socioemotional adjustment. J Pers 2003; 71(6):1197-1232.

13. Lee YJ, Seol DH, Cho SN. International marriages in South Korea: the significance of nationality and ethnicity. J Popul Res 2006;23(2):165-182.

14. Owusu A, Hart P, Oliver B, Kang M. The association between bullying and psychological health among senior high school students in Ghana, West Africa. J Sch Health 2011;81(5): 231238.

15. Eaton DK, Kann L, Kinchen S, Shanklin S, Flint KH, Hawkins J, et al. Youth risk behavior surveillance - United States, 2011. MMWR Surveill Summ 2012;61(4):1-162.

16. Rogers W. Regression standard errors in clustered samples. Stata Tech Bull 1994;3(13):19-23.

17. Williams RL. A note on robust variance estimation for clustercorrelated data. Biometrics 2000;56(2):645-646.
18. Umaña-Taylor AJ, Updegraff KA. Latino adolescents' mental health: exploring the interrelations among discrimination, ethnic identity, cultural orientation, self-esteem, and depressive symptoms. J Adolesc 2007;30(4):549-567.

19. Zeiders KH, Doane LD, Roosa MW. Perceived discrimination and diurnal cortisol: examining relations among Mexican American adolescents. Horm Behav 2012;61(4):541-548.

20. Tobler AL, Maldonado-Molina MM, Staras SA, O'Mara RJ, Livingston MD, Komro KA. Perceived racial/ethnic discrimination, problem behaviors, and mental health among minority urban youth. Ethn Health 2013;18(4):337-349.

21. Caputo RK. The effects of socioeconomic status, perceived discrimination and mastery on health status in a youth cohort. Soc Work Health Care 2003;37(2):17-42.

22. Berkel C, Knight GP, Zeiders KH, Tein JY, Roosa MW, Gonzales $\mathrm{NA}$, et al. Discrimination and adjustment for Mexican American adolescents: a prospective examination of the benefits of culturally-related values. J Res Adolesc 2010;20(4):893-915.

23. Tummala-Narra P, Claudius M. Perceived discrimination and depressive symptoms among immigrant-origin adolescents. Cultur Divers Ethnic Minor Psychol 2013;19(3):257-269.

24. Sangalang CC, Gee GC. Racial discrimination and depressive symptoms among Cambodian American adolescents: the role of gender. J Community Psychol 2015;43(4):447-465.

25. Kim SS, Chung Y, Subramanian SV, Williams DR. Measuring discrimination in South Korea: underestimating the prevalence of discriminatory experiences among female and less educated workers? PLoS One 2012;7(3):e32872.

26. Crosby F. The denial of personal discrimination. Am Behav Sci 1984;27(3):371-386

27. Krieger N. Embodying inequality: a review of concepts, measures, and methods for studying health consequences of discrimination. Int J Health Serv 1999;29(2):295-352.

28. Sellers RM, Copeland-Linder N, Martin PP, Lewis RH. Racial identity matters: the relationship between racial discrimination and psychological functioning in African American adolescents. J Res Adolesc 2006;16(2):187-216.

29. Harris R, Cormack D, Tobias M, Yeh LC, Talamaivao N, Minster J, et al. The pervasive effects of racism: experiences of racial discrimination in New Zealand over time and associations with multiple health domains. Soc Sci Med 2012;74(3):408-415. 